\title{
A hybrid of Delphi, AHP and TOPSIS Methods for project portfolio management
}

\author{
Ahmad Borjy ${ }^{\text {a }}$, Vahid Baradaran ${ }^{\mathrm{b}}$, Peyman Zandi ${ }^{*}$ and Milad Taheri $^{\mathrm{d}}$
}

${ }^{a}$ Industrial Engineering, North Tehran Branch, Islamic Azad University, Tehran, Iran

${ }^{b}$ Assistant Professor, Industrial Engineering department, North Tehran Branch, Islamic Azad University, Tehran, Iran

'Industrial Management department, Allameh Tabatabai University, Tehran, Iran

${ }^{d}$ Management department, University of Tehran, Tehran, Iran

\section{H R O N I C L E}

Article history:

Received: October 22018

Received in revised format: November 192018

Accepted: January 102019

Available online:

January 112019

Keywords:

Ranking investment projects

Portfolio of projects

$A H P$

TOPSIS

Delphi

\section{A B S T R A C T}

Due to the importance and complexity of the portfolio management issue, over 100 different techniques have already been presented. In general, the final result of these tools is to create a prioritized list of the projects that must be selected for allocating resources. The use of financial strategies may be misleading in some cases, and it is necessary to combine these methods with other methods such as strategic approaches in order to guarantee a balanced portfolio toward the organizational strategies. On the other, categorizing projects into different baskets allows the organizations to select, evaluate and prioritize the projects in a subset using a set of similar criteria and techniques. In this article, by choosing agriculture sector as a case study, an attempt has been made to study the evaluation, ranking and management of projects with investment classifying strategy of the projects using Delphi, TOPSIS and AHP methods. The results reveal that in similar cases we can use the presented model by determining the type of activity and investment and localization of the indexes.

\section{Introduction}

In terms of definition, the groups of projects that are being administered in an economic unit with similar strategic goal are called project basket or project portfolio. Management of portfolio is one of the challenging issues of decision- making in modern business (Cooper, 1997; Sommer, 1999). Nowadays, organizations have a large number of projects including development investments, performance improvement, etc. and since financial resources are always limited and the financial needs of different projects are unlimited, thus, decision- making, selection, determining priorities and ontime allocation of financial resources to ongoing projects of the organization can have significant effects on the growth of production and income and as a result in the development of the organization. Lack of right management and organizational projects basket will lead to reduction in competitiveness and their market share and in the end, their removal from competition cycle. In general, organizations can manage one or a reasonable number of projects but when the number of projects rises or the projects become more complex, they must compete in an environment with limited resources, challenges emerge (Levine, 2005). Lack of a definite system for selecting and omitting 
projects in companies and organizations results in unspecific selection of projects and personal taste, and companies administer and support projects that are not in accordance with their long-term and strategic goals, or they do not create the maximum profit for the organization. Thus, right prioritizing of projects is among the issues that managers are encountered with in selecting and compiling the documents of the projects in organizations. An evaluation of the publicity of the techniques shows that using financial approaches does not lead to efficient portfolio since financial approaches are dependent on financial information and may not present acceptable financial results in research and development or in innovative projects where uncertainty of information is higher (Cooper et al., 2002). Thus, although the issue of profit of the projects has always been a criterion for sooner completion of projects, in the concepts of projects portfolio management, the conformance of goals and strategies of the organization must be considered parallel to financial criteria. On the other hand, the social aspects and the dependence of projects on the management of the portfolio should not be ignored (Kester et al., 2011). Considering above concepts, it could be said that the willingness of the organizations for combining different methods for achieving requirements that guarantees success in selecting and determining priorities of projects has increased in a way that the use of an integrated, user-friendly and interactive system based on decision support system has also been recommended. Presenting a general and comprehensive system that can be used by organizations interested in the portfolio management of the projects, can play a key role in developing management (Cooper et al., 1999; Meredith et al., 2008; Lawson et al., 2006; Henriksen \& Traynor, 1999; Pinto \& Morris, 2004, Verbano \& Nosella, 2010; Ghasemzadeh \& Archer, 2000). Numerous books and articles have already been published on evaluation and selection of projects where more than 100 different techniques have been mentioned for evaluation and selection of basket of projects (Cooper, 1993; Zidane et al., 2016). Also these techniques could be divided into two main groups: Techniques for measuring profit and techniques for selecting projects and allocating resources (Baker \& Freeland, 1975). The first group mostly emphasizes the evaluation of individual projects (according to economic principles, etc.), whereas the second group mainly focuses on the development of portfolio from evaluations made on projects. In another evaluation by Dutra et al. (2014), the model and methods of projects selection have been divided into three groups, that is, qualitative approaches (such as balanced score card, bubble chart, Fuzzy logic, Delphi method, etc.), quantitative approaches (such as coverage data analysis, dynamic planning and integer, financial analysis, etc.) and compound approaches (such as decision tree, rural networks, etc.). It can be said that attempts made in the field of portfolio management have been based on below four objectives:

1) Maximizing the value of portfolio considering the resources

2) Balancing and selecting the right combination of projects

3) Accessing a portfolio toward strategies

4) Accessing a suitable number of projects given the limited financial resources (Cooper, 1997, 1999, 1998, 2000)

\section{Investment projects in multiple portfolios}

Given the large number of methods, there is no agreement on the point that which method is more effective. Also, practical use of these methods has not been considerable since most of these methods have been difficult and complex for understanding and using and in some cases, they require considerable input data. Hence, to decide properly in regard with projects, it is necessary that a clear definition of the methods be used for supporting the decision-makers and the methods be used for measurement of portfolio that is perceivable for decision-makers (Kerzner, 2006; Liesio et al., 2007; Meredith \& mantel, 2008; Eik-Andresen et al., 2016). For example, we can refer to studies by Cooper et al. (2001) that have addressed the selection and prioritizing of the projects (Poh et al., 2001; Henriksen \& Traynor, 1999; Meade \& Presley, 2002; Padovani et al., 2001). One of the important cases in establishing the management system of the project basket is choosing an appropriate framework proportionate to the type and conditions of the organization. Conformity of the model 
used to the conditions of the organization is very important since considering the nature of different fields and professions and complexity of some of the methods, basically presenting a general model for choosing projects in all organizations will not be efficient enough since managers and decision - makers should use or apply methods that have more conformity with their organizations on one hand, considering the wide range of investment fields and the possibility of different fields or professions in organizations, basically comparing all investment projects with each other, given the similar qualitative and quantitative criteria is not logical for prioritizing of projects and it is necessary at first to classify different recommended investment projects according to the properties of each type of investment basket (Skaf, 1999; Martikainen, 2002). Then, the qualitative and quantitative indexes of the investment must be considered based on the conditions of the organization. In this way, the classification of investment projects can be considered as the first step prior to evaluating the projects. This classification will also be useful in balancing the basket of projects.

Skaf (1999) defined portfolio management at two levels of business portfolio and investment portfolio for each business unit. According to this approach, the objective of group level (parent organization) is created by appropriate combination of business units and investment portfolio focuses on efficient allocation of resources in each business unit; This means that for better management of project portfolios, it is necessary to define the aim of the organization and the type of investment in each field or profession facilitates achieving this goal. The suggested approach for choosing the number of portfolios depends basically on the size of the organization, the variety of businesses and different types of investments in an organization. After carrying out studies in this field, and according to Table 1, four important approaches can be considered in classifying the group portfolio:

Table 1

Types of investment portfolio (Martikainen, 2002)

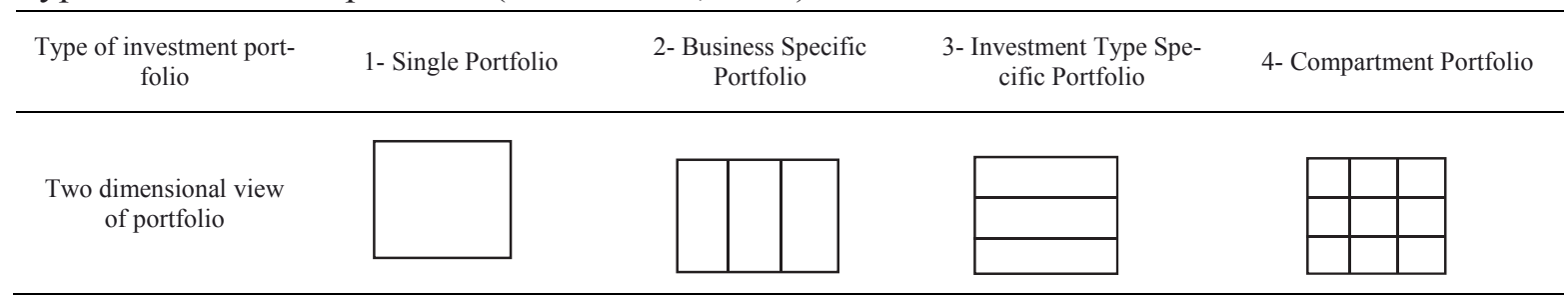

1) Single portfolio: is easier for small organizations with variety of activities, meaning, all investments in one basket must be compared with each other.

2) Portfolio based on business: if the organization has several fields of business each with its own strategic aims and definite independence level, thus, it has completely similar investments inside the business fields, and the use of portfolio based on business can be suitable in this case. In this case, group portfolio consists of some business unit portfolios.

3) Portfolio based on type of investment: if there is just one type of business in the organization but there is the possibility of different investments in this business, it is suggested that the portfolio be used according to investment type. In this approach, different portfolios will be available for different types of investments (such as investments for research and development or R \& D, combination and acquisition, infrastructure investment, etc.).

4) Compound portfolio: In the end, compound portfolio, is a combination of approaches 2 and 3 . Considering the size and properties of the organization, one of the portfolios should be selected for the organization according to Table 1 (Martikainen, 2002). Given the point that the field of agriculture has been selected as the case study, it consists of two separate businesses (agriculture and horticulture) and different types of investment. The model presented in this article is based on compound portfolio (as it was mentioned earlier, this approach will play an important role in the evaluation, determining priorities and selection of projects). Creating and adopting a suitable and required 
pattern that can evaluate the suggestions of different projects and type of portfolio of the organization conforming to the strategies of the organization is one importance roles of managers (Summer, 1999). Existence of a base and definite framework for controlling and selecting portfolio performance of the projects, provides the mangers of the organization with the assurance that different projects of the organization are carried out toward the aims of the organization (Rajegopal et al., 2007). Thus, the concept of integrating strategic orientation should be considered in conformity with forming investment baskets. Given the literature of the issue, there are two ways for integrating aims in strategic orientation: Bottom - up approach and creating strategic criteria in project selection tools (Cooper et al., 2002).

\subsection{Top-down approach (strategic bucket approach)}

In bottom-up approach, strategic adaptation is easily achieved by considering some strategic criteria inside the selection tools and determining priorities. Top-down approach starts with business strategy and then definite financial resources are considered or allocated for different types of projects inside a bucket. Top-down approach ensures that the portfolio of selected projects reflects exactly the strategies stated for business. The place where the resource is spent is a reflection (mirror) of business strategy (Cooper et al., 2002). In this article, an attempt is made to achieve a comprehensive model for evaluation, ranking and management of investment projects using the strong points of the methods and frameworks presented in regard with project basket. The model presented in this study uses qualitative and quantitative combined criteria (financial and strategic) together and ensures the strategic adaptation of the projects. In this investigation, the importance of financial criteria is determined using hierarchical analysis process and also the degree of qualitative criteria is determined using Delphi method. TOPSIS (The Technique for Order of Preference by Similarity to Ideal Solution) method was used to evaluate and rank the projects in each group of investments. The desired model in this study was implemented and described step by step in agriculture sector. Results show that the recommended model can be used or implemented in other similar organizations and meet some part of the need in project-oriented organizations in today's world. In the following, the recommended model based on classification approach of projects is presented.

\section{Methods and Materials}

After presenting the importance of suitable portfolio for organization, we implement this approach for the selected case study in an agricultural organization. The organization selected as the case study, is active in agriculture sector and consists of two different fields of activities (agriculture and horticulture) and a large number of projects in regard with different types of investments. In this research the views of 30 experts in the field of agricultural are used and Fig. 1 summarizes personal characteristics of the participants.

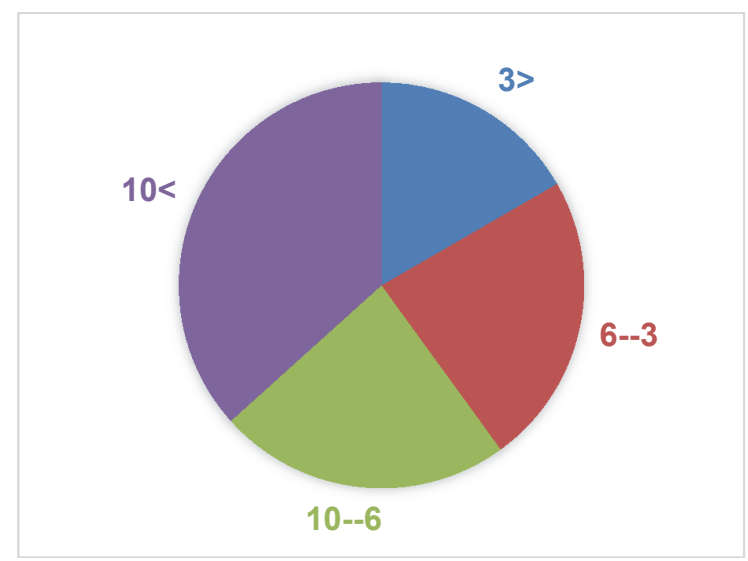

Years of Job Experience

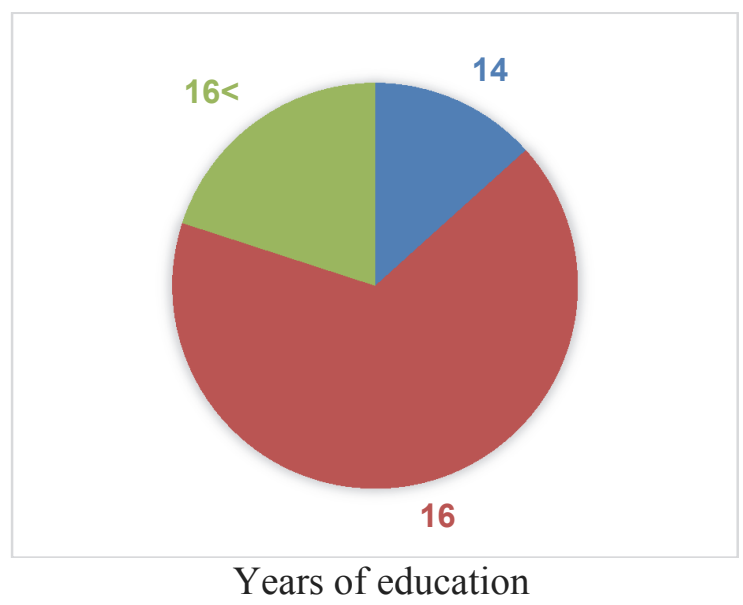

Years of education

Fig. 1. Personal characteristics of the participants 
In important stages of decision making, the views of 8 out of 30 experts ( 8 more important experts and beneficiary in the process for evaluation and ranking of projects) have been used. In the following, the stages of presenting a model will be presented in the form of stages in Fig 2.

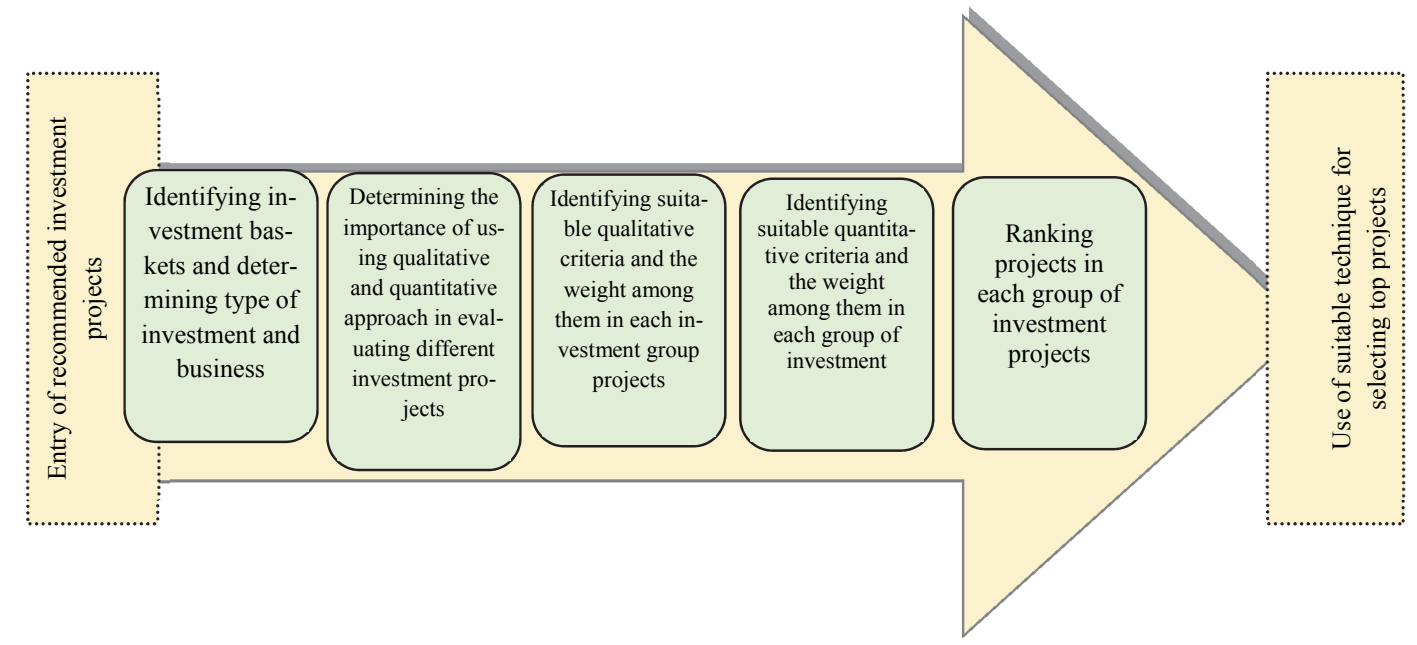

Fig. 2. Four steps for categorizing, evaluating and selecting investment projects

First step: identifying investments baskets (types of investment and business)

In this section, it is necessary to determine the classification and the project location in recommended grouping. Given the variety of businesses in the organization and variety in investment in each field of businesses, this classification has been presented and will be explained in the next sections. In this section, conformity of projects with mission, prospects and strategies of the organization will be explained. If a project is not in conformity with the mission and prospects and strategies of the organization, it will be omitted in this stage (Skaf, 1999; Martikainen, 2002). Also, the financial resource approach considered for each group of investments will be determined in this stage using organizational strategies (Cooper et al., 2002).

Considering the selected case study, two types of business have been recognized for this case study (agriculture and horticulture). In terms of the type of investment, given the case study conducted and the use of views of experts in this field of business, it was revealed that all projects in agriculture sector can be included in four general groups; that is, obligatory investment, developmental and promising investment, R\&D investments and recovery and improvement investment in a way that all projects of agriculture sector are replaceable in recommended classification. In the following, four types of investment projects identified for agriculture sector confirmed by industry experts, are described.

- Obligatory projects that are raised on the side of parent organization refer to projects that in case of implementation that provide the organization with much revenues although these revenues are not computable and measurable quantitatively. If they are not implemented, the organization encounters problems such as losing and decreasing water resources. It is notable that all obligatory projects will be selected for implementation. Hence, their implementation priority is determined given their evaluation results.

-Developmental and promising projects, projects consisting of market development, development of products in relation with business and capacity development. Projects such as cultivation gardens fall into this group.

- Research and development projects consisting of projects with risk and lack of higher certainty that have higher expected efficiency level and the organization has little experience about the implementation and administration and the technology used in these projects creates competitive advantage compared to other projects. These types of projects have higher complexity compared to other projects. Thus, the strategic orientation of the organization is more sensible in these types of 
projects, projects like construction of green house for seeding production are grouped in this category.

- Land reclamation investment has consisted of projects which are conducted for preservation and continuity of production. In other words, this group consists of investments for the purpose of continuing company activities. For example, in agriculture sector, investment in lands for the purpose of improving the quality of soil and drainage are considered among the projects of this group of investment.

In the end, given the point that the projects inside a basket compete with each other for obtaining resources, projects with similar investment and field of business, must be put inside the same basket. In Table 2, compartment portfolio has been considered that is observable for case study in agriculture sector. Given the points mentioned, it is concluded that evaluation and ranking indexes of projects are different in various investment groups that are discussed in the following.

\section{Table 2}

Suggested category for projects as case study in agriculture sector

\begin{tabular}{|c|l|c|}
\hline \multirow{2}{*}{ Type of businesses } & \multicolumn{2}{|c|}{ Mission, prospect and strategy of organization in two businesses } \\
\cline { 3 - 3 } Type of investments & $\begin{array}{c}\text { Business unit } 1 \\
\text { (Agronomy) }\end{array}$ & $\begin{array}{c}\text { Business unit2 } \\
\text { (Horticulture) }\end{array}$ \\
\hline Obligatory & & \\
\hline Development and promising & & \\
\hline Research and development or R \& D & & \\
\hline Land reclamation investment & & \\
\hline
\end{tabular}

Second step: Determining the importance of qualitative and quantitative approaches in evaluation of different investment projects.

According to studies carried out by Dutra et al. (2014), on evaluation of projects, three groups of qualitative, quantitative and combined approaches have been used. Although financial criteria are considered among the major factors in prioritizing projects, the projects cannot be evaluated and prioritized using only these criteria. Thus other cases such as alignment with applied missions (programs), balance between different types of investment projects, etc., should also be considered (Levine, 2005). Given this point and literature review of the topic, it was revealed that combined approaches show (produce) better results in practice. Therefore, two general groups of quantitative (financial approaches) and qualitative (strategic approaches) criteria are considered for evaluating projects. Each of these criteria can be used in combined form given different investments. Thus, it is required to determine the criteria used and their importance in each category of the investments. Since all projects are not similar, we must have a portfolio and qualification model for any type of projects (Cooper et al., 2002, 2006; Levine, 2005). For example, some types of projects called preservation projects exist that support the products and continuous services. If these projects are prioritized by the same criteria as other projects, they may not achieve much rank in the profit value section, and if a threshold is considered for NVP (Net present value) index, they may not pass screening stage; however, if these kinds of projects are rejected, it may incur losses for the organization. Hence, these obligatory projects will be evaluated using different aims and indexes. Also, it is possible that the internal rate of return or net present value could not be measured accurately (Levine, 2005), In such cases, like R\&D projects, lack of certainty is high due to the novelty of the projects and the use of qualitative criteria is more appropriate (Cooper et al., 2002, 2006). Therefore, these types of projects cannot be combined with other cases or a similar evaluation pattern cannot be used. Thus, by studying the literature of the subject and using the opinions of 30 experts, it was concluded that in new projects like R\&D due to the lack of certainty, the use of qualitative criteria is more appropriate. Also, it is far better to evaluate obligatory projects with qualitative approaches such as strategic indexes. The importance of quantitative indexes for developmental and promising 
projects and also recovery and reclamation projects is much more compared with qualitative indexes. Since uncertainty of the data is not significant. Fig. 3 represents the degree of importance of qualitative and quantitative indexes (financial and strategic) for evaluating Projects.

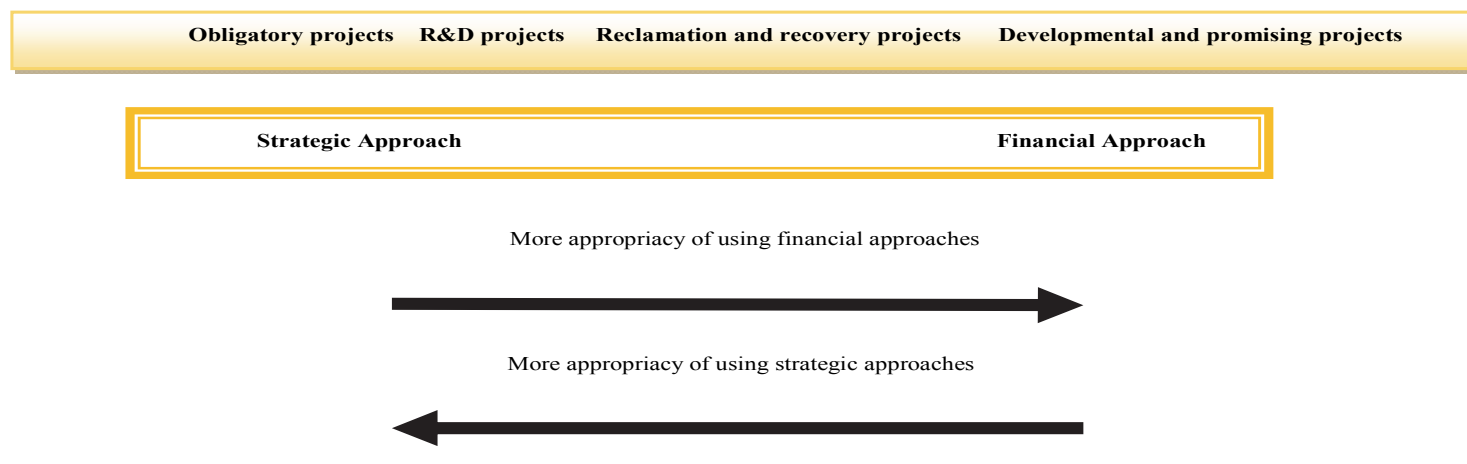

Fig. 3. The importance of financial and strategic approaches in evaluation of different investment projects

As it is clear in developmental and promising projects, the degree of importance of financial approaches is more and in obligatory projects the importance of using strategic approaches is more. In the following, it is necessary to decide on the degree of importance of financial and strategic criteria in different investment projects. In this field, the opinions of 8 experts were used. Table 3 shows the degree of importance of financial and strategic criteria in different investment groups.

\section{Table 3}

The degree of importance of financial and strategic criteria in different investment groups in agriculture sector

\begin{tabular}{ccccc}
\hline & \multicolumn{3}{c}{ Investment type } \\
\cline { 2 - 4 } Evaluating criteria & Obligatory & R\&D & Reclamation and recovery & $\begin{array}{c}\text { Developmental and } \\
\text { promising }\end{array}$ \\
\hline Financial criteria & $0 \%$ & $20 \%$ & $60 \%$ & $65 \%$ \\
Strategic criteria & $100 \%$ & $80 \%$ & $40 \%$ & $35 \%$ \\
\hline
\end{tabular}

The following important points can be stated about different financial and strategic criteria:

- To make a comparison among different projects, it is required that a conventional measurement system be established (Meredith, 2006; Kerzner \& Mantel, 2008; Cooper et al., 2000).

- To ensure the maximum efficiency for a category of selected projects, fixed and related criteria with business strategies of the organization must be used in selection process (Pinto \& Morris, 2004; Meade and Presley, 2002). This leads to logical competition among projects.

Moreover, information available for decision-makers (DM) is not generally complete. Thus, the criteria should be selected that required information about them is achievable.

- Also, there should be a clear definition of the criteria used for supporting decision-makers since criteria for checking a portfolio is only applicable if they are perceivable for decisionmakers (Kerzner, 2006; Liesio et al., 2007; Meredith \& Mantel, 2008; Tzeng \& Huang, 2011).

However, there is not an agreement over the point that what criteria must be used. As a result, each organization tends to choose criteria that have the highest importance to the organization. Incorrect choice of decision-making indexes can lead the organization toward bankruptcy in achieving the strategic objectives (Padovani et al., 2010). In the following, the method of selecting financial and strategic indexes and their evaluation are discussed. 


\section{Third step: Identifying appropriate financial criteria and their importance factor in each cat- egory of investments}

Considering the literature review about financial criteria used in single evaluation of projects and the use of an open questionnaire and the opinions of 30 experts in investment ultimately, 10 financial criteria of higher importance were identified. Then, two steps were taken to obtain more appropriate indexes. 1- Eight main experts were separately given a questionnaire consisting of all desired criteria and each member of the group was asked to assign a score from 1 to 10 to each of the criteria. After completing the questionnaire, the result was confirmed using the statistical analysis software SPSS in terms of reliability (Cronbach Alpha for questionnaire result was 0.722).

2 - Then, the questionnaire consisting of the scores of the group members, were collected in a central station and the mean of points obtained for each criterion from experts' opinions was determined, and the criteria that achieved higher than 7 were selected as the final criteria (Azar \& Rajabzadeh, 2012). So out of 10 criteria, 5 more important criteria were obtained for using in decision-making and the validity of selected criteria was confirmed by experts. Results are observable in table 4.

\section{Table 4}

Obtained financial criteria by using literature review and experts opinions

\begin{tabular}{|c|c|c|c|c|}
\hline Raw & Criteria & Definition & Average rating & $\begin{array}{l}\text { Accepted/ } \\
\text { Rejected }\end{array}$ \\
\hline 1 & IRR or IRRE & $\begin{array}{l}\text { IRR is the interest rate at which the net present value of all the cash flows (both posi- } \\
\text { tive and negative) from a project or investment equal zero (NPVE }=0)\end{array}$ & 8.8 & $\checkmark$ \\
\hline 2 & API & Mean of profit index or annual current value of investment & 4.8 & $x$ \\
\hline 3 & PBP-s & $\begin{array}{l}\text { The payback period (PBP) is defined as the period of time (in years) required to break } \\
\text { even on the initial economic investment. (without considering time value of money) }\end{array}$ & 7.6 & $\checkmark$ \\
\hline 4 & NPVE/TC & Profitability index $=$ present value of future cash flows / initial investment & 8.4 & $\checkmark$ \\
\hline 5 & ARR & $\begin{array}{l}\text { Accounting rate of return (ARR) is the ratio of estimated accounting profit of a project } \\
\text { to the average investment made in the project }\end{array}$ & 6.2 & $x$ \\
\hline 6 & $\mathrm{~B} / \mathrm{C}$ & The total discounted benefits are relative to the total discounted costs & 5.1 & $x$ \\
\hline 7 & NPV or NPVE & $\begin{array}{l}\text { Net Present Value (NPV) is the difference between the present value of cash inflows } \\
\text { and the present value of cash outflows }\end{array}$ & 9.8 & $\checkmark$ \\
\hline 8 & $\begin{array}{l}\text { Operating margin } \\
\text { ratio }\end{array}$ & $\begin{array}{l}\text { A profitability ratio that measures what percentage of total revenues is made up by } \\
\text { operating income }\end{array}$ & 4.8 & $x$ \\
\hline 9 & $\begin{array}{l}\text { Share of facilities } \\
\text { relative to the fi- } \\
\text { nancing }\end{array}$ & The amount of project's financial facility relative to the obtaining project's financing & 4.2 & $x$ \\
\hline 10 & ROI & $\begin{array}{l}\text { Return on investment (ROI) measures the gain or loss generated on an investment } \\
\text { relative to the amount of money invested }\end{array}$ & 8.1 & $\checkmark$ \\
\hline
\end{tabular}

In the next stage, the importance weight of financial criteria (IRRE, PBP-S, NPV, NPVE/ TC, ROI) must be determined. To find a suitable model, care must be taken that, in general, there is not a special rule or universal prescription for this purpose, the judgment of the experts and methods such as brain storming, Delphi, etc., have been developed. In this study, AHP (Analytic Hierarchy Process) method due to its hierarchical structure and possibility of reviewing tangible and non-tangible factors, has been recognized as an appropriate method for determining the weights of financial criteria whose stages are explained in the following. Hierarchy analysis process was first raised by Saaty in 1980 and has had plenty of applications in solving managerial, economic and social problems. Hierarchy analysis process provides a structure and framework for group cooperation and participation in making discussions or solving problems. There are three basic principles in analytical thinking of an AHP technique: principle of hierarchy tree drawing, determining priorities and principle of logical compatibility judgment (Azar \& Rajabzadeh, 2012). Therefore, at first, the hierarchy structure for determining the weights of financial criteria was considered as Fig. 4.

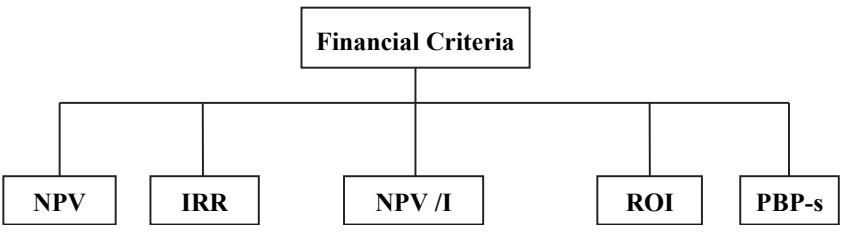

Fig. 4. Hierarchy structure for determining weights of financial criteria 
In hierarchy analysis process, measuring the values of relative importance and priorities from pair comparison of its criteria is done relative to choices or criteria and using spectrums from 1 to 9 , where 1 is indicative of equal weight between two factors and 9 is indicative of the high importance of a factor relative to another factor. Thus, given the hierarchy structure of financial criteria, a questionnaire was designed. Then 8 experts in the field of investment and portfolio management were asked to state separately the relative weight of each pair of financial criteria pair to pair using a 9 degree scale and give it to the researcher. In this way, the viewpoints of experts were collected in the form of a questionnaire that has been summarized in table 5. Then, the data of the table were given to EXPERT CHOICE software and the results were obtained using GAHP (Group Analytic Hierarchy Process) as Fig. 5.

\section{Table 5}

Comparison of different financial criteria

\begin{tabular}{cccccc}
\hline & NPV & NPVE/I & IRR & PBP-S & ROI \\
\hline NPV & $(1,1,1,1,1,1,1,1)$ & $(3,2,1,2,1,0.5,0.5,1)$ & $(2,1,0.5,1,3,1,1,2)$ & $(3,2,1,3,3,3,3,2)$ & $(4,3,2,3,4,2,2,2)$ \\
NPV/ I & & $(1,1,1,1,1,1,1,1)$ & $(1,0.5,0.5,0.5,2,3,3,2)$ & $(2,3,1,2,3,2,2,1)$ & $(3,3,2,4,4,1,1,2)$ \\
IRR & & & $(1,1,1,1,1,1,1,1)$ & $(2,3,2,2,1,3,3,2)$ & $(1,3,2,3,2,1,1,3)$ \\
PBP-S & & & & $(1,1,1,1,1,1,1,1)$ & $(1,2,2,1,0.5,0.5,0.5,0.5)$ \\
ROI & & & & $(1,1,1,1,1,1,1,1)$ \\
\hline
\end{tabular}

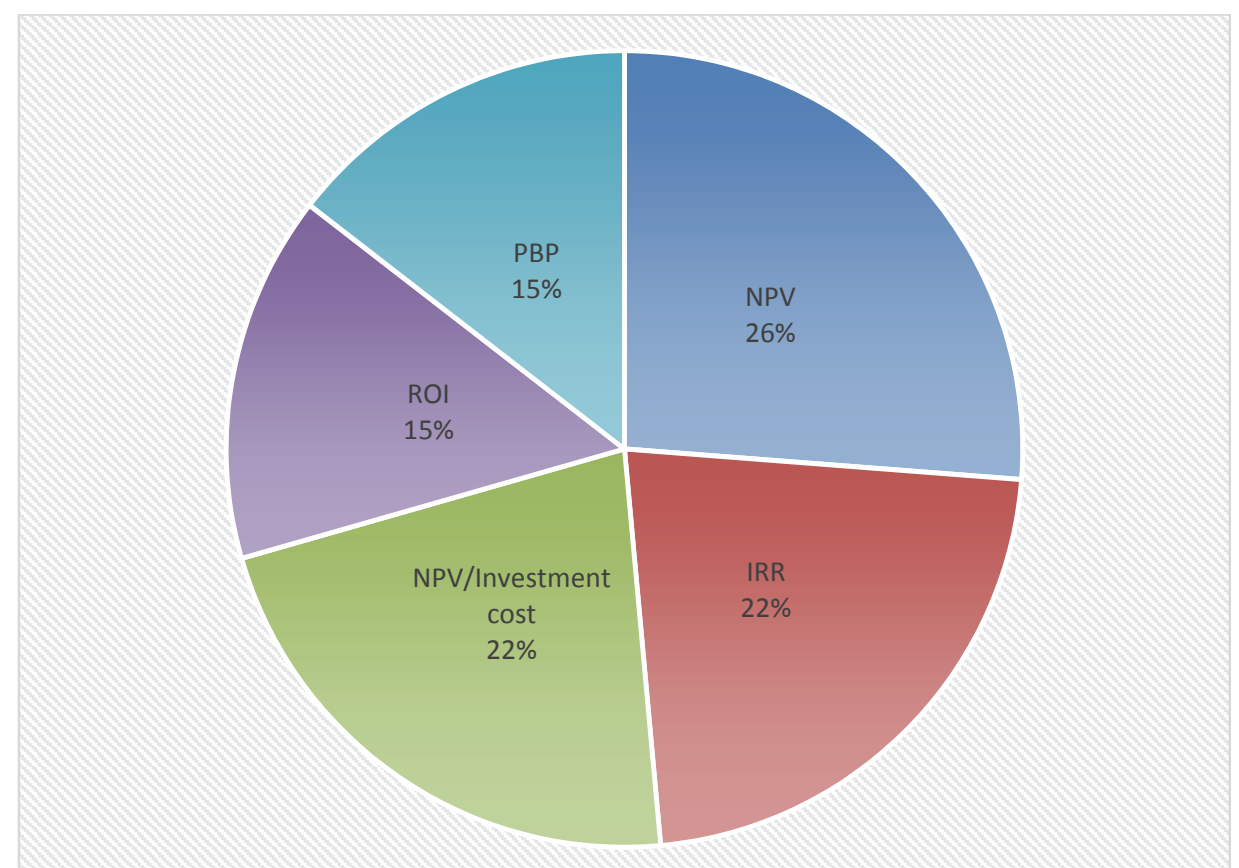

Fig. 5. Weight obtained for financial criteria using expert choice software $(C R=0.05)$

In AHP method we can ensure precision of responses of experts by calculating incompatibility rate. Compatibility ratio 0.1 or less, states acceptable compatibility rate in paired comparisons (Saaty, 1990). If compatibility rate is more than 0.1 , judgments may be contradictory and they have to be reconsidered. As it is clear in the output of this analysis, incompatibility rate is less than 0.1 and thus, it is not necessary to reconsider the questionnaires. In the next stage, the weight of each of the financial criteria has to be obtained in a way that total financial weights in each type of investment has to be according to the values obtained in Table 3 in previous selection. Table 6 was obtained based on these issues. 
Table 6

Weights of financial criteria in each of investment group

\begin{tabular}{|c|c|c|c|c|c|c|c|c|}
\hline \multirow[b]{2}{*}{ 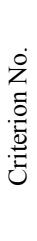 } & \multirow[b]{2}{*}{ Criteria } & \multirow[b]{2}{*}{$\begin{array}{l}\text { Weight } \\
\text { resulting from } \\
\text { AHP }\end{array}$} & \multicolumn{6}{|c|}{$\begin{array}{l}\text { Importance of financial criteria in different } \\
\text { investments }\end{array}$} \\
\hline & & & 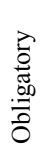 & $\hat{\otimes}$ & 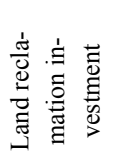 & 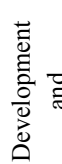 & & 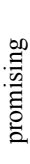 \\
\hline 1 & NPV & 0.262 & 0 & 0.052 & 0.157 & & 0.170 & \\
\hline 2 & IRR & 0.223 & 0 & 0.044 & 0.133 & & 0,144 & \\
\hline 3 & NPV / (Investment Cost) & 0.220 & 0 & 0.044 & 0.132 & & 0.143 & \\
\hline 4 & Net Profit Average ROI =/ (Investment Cost) & 0.149 & 0 & 0.029 & 0.089 & & 0.096 & \\
\hline 5 & PBP-s & 0.145 & 0 & 0.029 & 0.087 & & 0.094 & \\
\hline 6 & Total (in percent) & $100 \%$ & $\mathbf{0}$ & $20 \%$ & $60 \%$ & & $65 \%$ & \\
\hline
\end{tabular}

Fourth step: Identifying appropriate qualitative criteria and the weight between them in each group of investment

Qualitative criteria consists of criteria whose evaluation and measurement is difficult. Among qualitative criteria, the probable cases of success in technical terms, probability of success in market, profitability, size (amount) and need of market, organization's market share, accessibility of resources, degree of competitiveness, environmental limitations and organizational guidelines, recommended strategic orientation, product advantage, market attractiveness, the ability to create a competition, technical feasibility, risk and return, etc. can be considered as main criteria in qualitative evaluation of projects (Martino,1995; Dutra et al., 2014; Cooper et al., 1997 \& 1998).

In this section, 5 major qualitative criteria and 35 sub-criteria were selected by studying the literature review and opinions of 30 experts. Then the list of qualitative criteria was given to the 8member expert group for reviewing and final approval. At the end, the reviewed and improved list consisted of 20 qualitative criteria that have been described in Table 7. To find the weight among criteria in Table 7, Delphi method was preferred due to the large number of criteria and sub-criteria. Thus, after consulting with experts, the weight of each quality criterion was determined with the consensus of the group of eight experts for different investment projects according to Table 7, in a way that the total weight of quantitative criteria is based on Table 3 .

If it is observed that the weight of strategic criteria, relative advantage of product, market attractiveness, technology, risk and returns in four determined investment are different, it is indicative of the point that different qualitative criteria have to be used in different investment projects and the importance degree of these criteria can be different in various investment projects. 
Table 7

Qualitative indexes and their related weight using Delphi method in different investments

Importance of qualitative criteria

in different investments

\begin{tabular}{|c|c|c|c|c|c|}
\hline 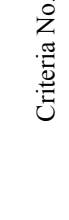 & Criteria & $\begin{array}{l}\overrightarrow{0} \\
\stackrel{0}{0} \\
.000 \\
0 \\
0\end{array}$ & के & 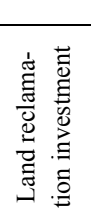 & 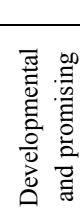 \\
\hline 1 & Strategic criteria & $80 \%$ & $40 \%$ & $22 \%$ & $20 \%$ \\
\hline $\mathrm{C} 11$ & $\begin{array}{l}\text { Matching with strategy 1: development of activity at economic } \\
\text { scales using update technology }\end{array}$ & $5 \%$ & $5 \%$ & $7 \%$ & $10 \%$ \\
\hline $\mathrm{C} 12$ & $\begin{array}{c}\text { Matching with strategy } 2 \text { : development of water resources and im- } \\
\text { proving their operation system }\end{array}$ & $15 \%$ & $5 \%$ & 0 & 0 \\
\hline $\mathrm{C} 13$ & $\begin{array}{c}\text { Matching with strategy } 3: \text { development of research and practical } \\
\text { training }\end{array}$ & $5 \%$ & $5 \%$ & 0 & 0 \\
\hline $\mathrm{C} 14$ & $\begin{array}{l}\text { Matching with strategy 4: product development (increasing product } \\
\text { supplying new products) }\end{array}$ & 0 & $5 \%$ & $6 \%$ & $\% 10$ \\
\hline $\mathrm{C} 15$ & $\begin{array}{c}\text { Matching with strategy } 5 \text { : product extension (quality improvement, } \\
\text { brand development) }\end{array}$ & 0 & $5 \%$ & 0 & 0 \\
\hline $\mathrm{C} 16$ & Social benefits & $15 \%$ & $3 \%$ & $4 \%$ & 0 \\
\hline $\mathrm{C} 17$ & Improving competitive advantage & $10 \%$ & $5 \%$ & 0 & 0 \\
\hline $\mathrm{C} 18$ & Job creation & $20 \%$ & $2 \%$ & 0 & 0 \\
\hline C19 & Effect of project on organization's business(es) & $10 \%$ & $5 \%$ & $5 \%$ & 0 \\
\hline 2 & Relative advantage of product & 0 & $10 \%$ & 0 & 0 \\
\hline $\mathrm{C} 21$ & Better response to customer needs & 0 & $5 \%$ & 0 & 0 \\
\hline $\mathrm{C} 22$ & Product differentiation from customer perspective & 0 & $5 \%$ & 0 & 0 \\
\hline 3 & Market attractiveness & 0 & $10 \%$ & $8 \%$ & $6 \%$ \\
\hline $\mathrm{C} 31$ & Market size, market growth and future potentials & 0 & $5 \%$ & $4 \%$ & $3 \%$ \\
\hline $\mathrm{C} 32$ & Possibility of rational competition in industry & 0 & $5 \%$ & $4 \%$ & $3 \%$ \\
\hline 4 & Technology & $20 \%$ & $15 \%$ & $5 \%$ & $5 \%$ \\
\hline $\mathrm{C} 41$ & Degree of organization business with technology & $4 \%$ & $4 \%$ & $2 \%$ & 0 \\
\hline $\mathrm{C} 42$ & Certainly of technology access & $6 \%$ & $4 \%$ & 0 & 0 \\
\hline $\mathrm{C} 43$ & Certainly of access to the quality and quantity of water resources & $6 \%$ & $2 \%$ & 0 & $2 \%$ \\
\hline $\mathrm{C} 44$ & appropriate atmospheric and soil conditions of area & 0 & $1 \%$ & $3 \%$ & $2 \%$ \\
\hline $\mathrm{C} 45$ & Access to raw material & $4 \%$ & $4 \%$ & 0 & $1 \%$ \\
\hline 5 & Risk and return in implemented similar projects & 0 & $5 \%$ & $5 \%$ & $4 \%$ \\
\hline C51 & Expected achievement rate & 0 & $2 \%$ & $4 \%$ & $3 \%$ \\
\hline \multirow[t]{2}{*}{$\mathrm{C} 52$} & Degree of certainty of profit and Returns estimation & 0 & $3 \%$ & $1 \%$ & $1 \%$ \\
\hline & Sum & $100 \%$ & $80 \%$ & $40 \%$ & $35 \%$ \\
\hline
\end{tabular}




\section{Fifth step: Ranking investment projects in each investment group}

In regard with project selection, Liesio (2007) suggested that simple and clear strategies that consider multiple criteria can be accepted by business decision-makers, even these criteria require much information. In this stage, given the criteria and qualitative and quantitative sub-criteria and weights obtained in previous stages, the ranking of projects in each investment group is taken down. For this purpose, TOPSIS technique will be used according to experts' opinion. This method was presented by Hwang and Yoon (1981) and consists of following implementation stages:

Step (1): creating the decision-making matrix:

The structure of this matrix is given as follows,

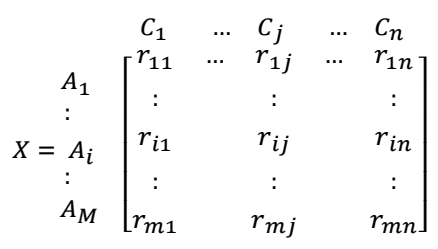

where $r_{i j}$ shows the value of $A_{i}$ (Alternative) based on $C_{j}$ (Criteria).

Step (2): Calculating normalized evaluation matrix. The aim of this step is to draw normalized matrix with values between 0 and 1 . In this way, the normalized value for each member of matrix is calculated in Eq. (1) as follows,

$$
r_{i j}=\frac{r_{i j}}{\sqrt{\sum_{i=1}^{m} r_{i j}^{2}}}, i=1, \ldots, m ; j=1, \ldots, n
$$

Step (3): Calculating normalized weight matrix. In this step with having the weight of criteria and normalized matrix, we calculate normalized weight matrix using Eq. (2):

$$
V_{i j}=W_{j} \times r_{i j}
$$

Step (4): Determining the positive and negative ideal limits. In this stage the positive and negative ideals are calculated using following relations:

$$
\begin{aligned}
& A^{+}=\left[\left(\max v_{i j} \mid j \in C_{b}\right),\left(\min v_{i j} \mid j \in C_{c}\right) \mid i=1, \ldots, m\right]=\left(v_{j}^{+} \mid j=1, \ldots, n\right) \\
& A^{-}=\left[\left(\min v_{i j} \mid j \in C_{b}\right),\left(\max v_{i j} \mid j \in C_{c}\right) \mid i=1, \ldots, m\right]=\left(v_{j}^{-} \mid j=1, \ldots, n\right)
\end{aligned}
$$

In a way that $\mathrm{C}_{\mathrm{b}}$ is the positive criteria and $\mathrm{C}_{\mathrm{c}}$ is negative ones.

Step (5): Calculating the distance of alternatives from positive and negative ideal limits by using following formulas:

$$
d_{i}^{+}=\sqrt{\sum_{j=1}^{n}\left(v_{i j}-v^{+}\right)^{2}} \quad \forall i
$$




$$
d_{i}^{-}=\sqrt{\sum_{j=1}^{n}\left(v_{i j}-v^{-}\right)^{2}} \forall i
$$

Step (6): Determining ranking criteria using proximity index. In this step, also each Investment projects will be ranked using following formula:

$$
c l_{i}^{+}=\frac{d_{i}^{-}}{d_{i}^{-}-d_{i}^{+}}
$$

$\mathrm{Cl}_{\mathrm{i}}^{+}$will be a value between zero and one. The closer the alternatives are to ideal solution; this value will be closer to one. In this study, decision-making matrix has been obtained by considering quantitative and qualitative criteria and final matrix showed in Table 8.

As it was revealed, the weight of each criteria in different types of investment is different and is determined based on the projects type of the portfolio. In regard with Table 8 , it is necessary to pay attention to following points:

- Weight of each of the quantitative criteria is achieved using paired comparison method and the weight each of the qualitative criteria and sub criteria has been achieved using Delphi method in previous steps.

- The weight of criteria and sub criteria in the evaluation of investment projects is determined based on the type of investment.

- Index nature refers to the nature of the indicators in either in the form of + (The more, the better) and or in the form of - (The less, the better).

- Given the different nature of projects in each portfolio, only same projects from the point of view of investment and business must be evaluated and compared in one portfolio.

Quantitative criteria such as NPV, IRR, etc., can be obtained from the output of Comfar software, also qualitative information of the projects by using of spectrums is achieved and can be converted into quantitative information.

Although, the best methods are methods that use distance and rating scales or bipolar scales. In this way, with algorithm formulation of TOPSIS in related software, investment projects in different groups are evaluated using the qualitative and quantitative criteria. Finally projects inside each portfolio are ranked and in the end, given the financial resources considered for each group (category), top projects in each investment category are chosen.

Table 8

Use of TOPSIS and weight obtained from AHP and Delphi methods for ranking projects

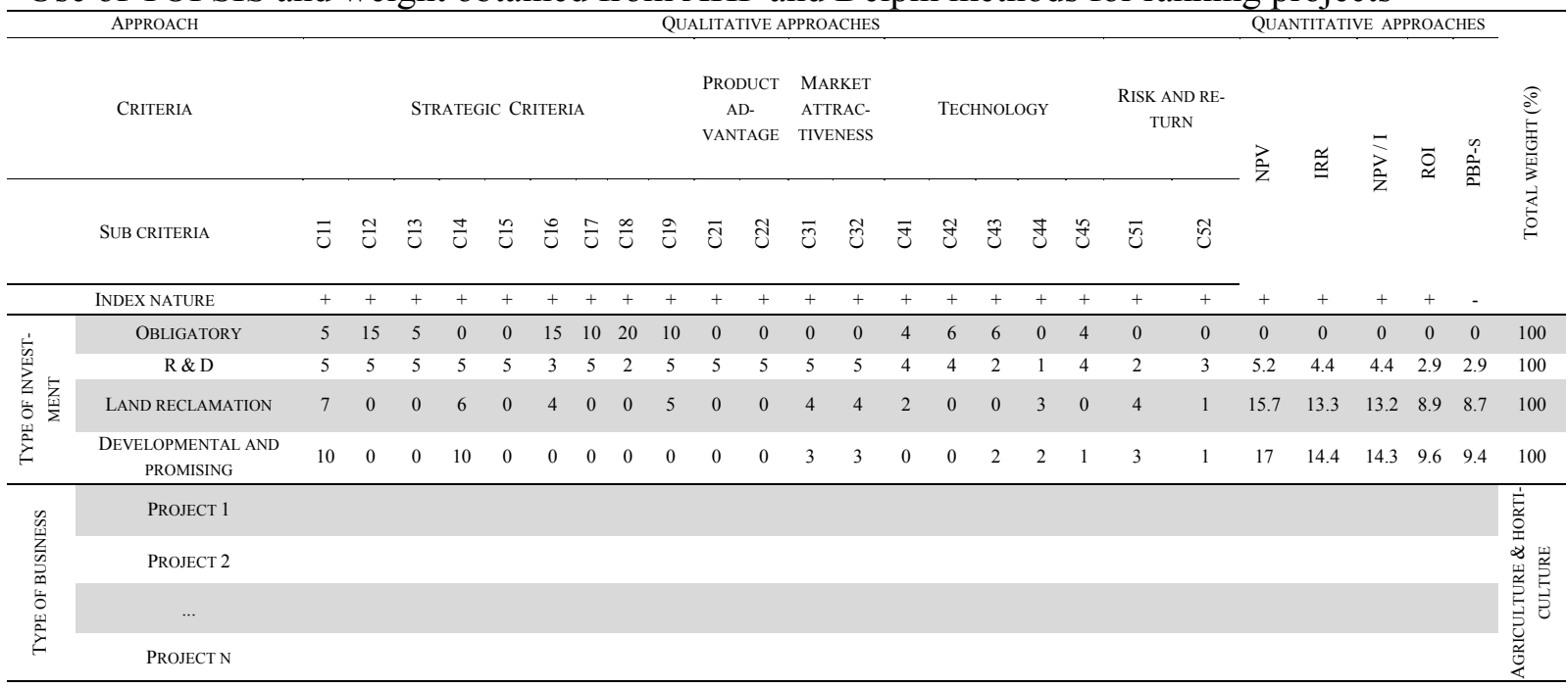




\section{Discussion and conclusion}

This article seeks to present an effective model by categorizing projects of investment in a case study in agriculture sector for evaluating and ranking of investment projects. It is obvious that the same approach cannot be used for comparing among all projects in decision-making process. For this purpose, a model has been presented for categorizing based on business and type of investment in agriculture sector (as case study). In this type of categorizing, an appropriate model has been presented for evaluating and selecting of investment projects. In presented model, the importance of qualitative and quantitative approaches has been described for evaluating of different types of investment projects. In this paper, an attempt is made to use bottom-up approach for a strategic alignment of projects with organization's goals and business strategic of the organization. Total allocable financial resources to each group are determined by top managers of organization. On the other hand, the top-down approach will play a critical role in strategic orientation of organization (Cooper et al., 2002).

In this article, the most important quantitative criteria that can be used in the evaluation of investment projects were identified using experts and AHP was used to calculate the importance factor of the criteria. Also the most important qualitative criteria were identified and selected using literature review and expert's opinions and were weighted using Delphi method. The best approach for evaluating and selecting of projects in an investment category is the use of combined approaches that in this paper, the importance of different criteria has been explained in evaluation of different types of projects. In this way, investment projects in different categories were evaluated and ranked using qualitative and quantitative criteria and TOPSIS technique.

In selection process of projects, Optimizing models (such as zero and one integer programming) are able to consider the interaction among projects such as resources dependency, budget constraints, technical and market interactions and program considerations (Martino, 1995).

If there are too many projects to be analyzed, we can omit the projects which are not in conformity with the missions of organization by initial review in order to make selection process simple (Pinto \& Morris, 2004). Hence, in this way, there will be less need to information about projects in order to put it into decision matrix. The balance between projects is an important issue that can be considered by focusing on different aspects such as the proportion of early return projects versus late return projects, the proportion of short term period projects versus long term period projects, the proportion of low risk projects versus high risk projects, etc. Although the model introduced for categorizing, evaluating and selecting projects in agriculture sector have been discussed, but the results of study can be generalized and developed and will be more tangibly analyzing through using appropriate techniques and real data related to the projects of an organization.

\section{References}

Azar, A., \& Rajabzadeh, A. (2009). Applied Decision Making MADM Approach. Negahe Danesh Puplication.

Baker, N., \& Freeland, J. (1975). Recent advances in R\&D benefit measurement and project selection methods. Management science, 21(10), 1164-1175.

Cooper, R. G., Edgett, S. J., \& Kleinschmidt, E. J. (1999). New product portfolio management: practices and performance. Journal of product innovation management, 16(4), 333-351.

Cooper, R. G., Edgett, S. J., \& Kleinschmidt, E. J. (2000). New problems, new solutions: making portfolio management more effective. Research-Technology Management, 43(2), 18-33.

Cooper, R., Edgett, S., \& Kleinschmidt, E. (2001). Portfolio management for new product development: results of an industry practices study. $r \& D$ Management, 31(4), 361-380.

Cooper, R. G., Edgett, S. J., \& Kleinschmidt, E. J. (2002). New problems, new solutions: making portfolio management more effective. Managing Multiple Projects: Planning, Scheduling, and Allocating Resources for Competitive Advantage, 181. 
Cooper, R. G., Edgett, S. J., \& Kleinschmidt, E. J. (2006). Portfolio Management for New Product Development.

Cooper, R. G. (2011). Winning at new products: Creating value through innovation. Basic Books.

Dutra, C. C., Ribeiro, J. L. D., \& de Carvalho, M. M. (2014). An economic-probabilistic model for project selection and prioritization. International Journal of Project Management, 32(6), 10421055 .

Eik-Andresen, P., Johansen, A., Landmark, A. D., \& Sørensen, A. Ø. (2016). Controlling a multibillion project portfolio-milestones as key performance indicator for project portfolio management. Procedia-Social and Behavioral Sciences, 226, 294-301.

Ghasemzadeh, F., \& Archer, N. P. (2000). Project portfolio selection through decision support. Decision support systems, 29(1), 73-88.

Henriksen, A. D., \& Traynor, A. J. (1999). A practical R\&D project-selection scoring tool. IEEE Transactions on Engineering Management, 46(2), 158-170.

Hwang, C. L., \& Yoon, K. (1981). Methods for multiple attribute decision making. In Multiple attribute decision making (pp. 58-191). Springer, Berlin, Heidelberg.

Kerzner, H. (2016). Gestão de Projetos-: As Melhores Práticas. Bookman Editora.

Kester, L., Griffin, A., Hultink, E. J., \& Lauche, K. (2011). Exploring portfolio decision-making processes. Journal of Product Innovation Management, 28(5), 641-661.

Lawson, C. P., Longhurst, P. J., \& Ivey, P. C. (2006). The application of a new research and development project selection model in SMEs. Technovation, 26(2), 242-250.

Levine, H. A. (2005). Project portfolio management: a practical guide to selecting projects, managing portfolios, and maximizing benefits. John Wiley \& Sons.

Liesiö, J., Mild, P., \& Salo, A. (2007). Preference programming for robust portfolio modeling and project selection. European Journal of Operational Research, 181(3), 1488-1505.

Martino, J. P. (1995). Research and development project selection. Wiley.

Martikainen, J. (2002). Portfolio management of strategic investments in metal products industry. Helsinki University of technology.

Meade, L. M., \& Presley, A. (2002). R\&D project selection using the analytic network process. IEEE transactions on engineering management, 49(1), 59-66.

Meredith, J. R., \& Mantel Jr, S. J. (2011). Project management: a managerial approach. John Wiley \& Sons.

Padovani, M., CARVALHO, M. M. D., \& Muscat, A. R. N. (2010). Seleção e alocação de recursos em portfólio de projetos: estudo de caso no setor químico. Gestão \& Produção, 17(1), 157-180.

Pinto, J. K., \& Morris, P. W. (2004). The Wiley guide to managing projects. Hoboken, NJ: Wiley.

Poh, K. L., Ang, B. W., \& Bai, F. (2001). A comparative analysis of R\&D project evaluation methods. $R \& D$ Management, 31(1), 63-75.

Rajegopal, S., McGuin, P., \& Waller, J. (2007). Project portfolio management: Leading the corporate vision. Springer.

Saaty, T. L., Rogers, P. C., \& Pell, R. (1980). Portfolio selection through hierarchies. The journal of portfolio management, 6(3), 16-21.

Saaty, T. L. (1990). How to make a decision: the analytic hierarchy process. European journal of operational research, 48(1), 9-26.

Skaf, M. A. (1999). Portfolio management in an upstream oil and gas organization. Interfaces, 29(6), 84-104.

Sommer, R. J. (1999). Portfolio management for projects: A new paradigm. Project Portfolio Management. Selecting and Prioritizing Projects for Competitive Advantage. West Chester, PA: Center for Business Practices.

Tzeng, G. H., \& Huang, J. J. (2011). Multiple attribute decision making: methods and applications. Chapman and Hall/CRC.

Verbano, C., \& Nosella, A. (2010). Addressing R\&D investment decisions: a cross analysis of R\&D project selection methods. European Journal of Innovation Management, 13(3), 355-379.

Zidane, Y. J., Johansen, A., Andersen, B., \& Hoseini, E. (2015). Time-thieves and bottlenecks in the Norwegian construction projects. Procedia Economics and Finance, 21, 486-493. 

article distributed under the terms and conditions of the Creative Commons Attribution (CC-BY) license (http://creativecommons.org/licenses/by/4.0/). 